\title{
De camino a una antropología semiótica: lectura teológica del signo*
}

\author{
Froilán Casas Ortiz ${ }^{* *}$
}

Recibido: 13 de febrero de 2013 • Aprobado: 28 de abril de 2013

\section{Resumen}

En este artículo el autor parte de un breve análisis del fenómeno de la postmodernidad, como un existenciario colectivo que incide en el modo de pensar del hombre contemporáneo. Argumenta su discurso desde la antropología semiótica, siendo el lenguaje y el signo un significante importante para la cultura de hoy. Desde este código ha hablado Dios a los hombres, y es justamente allí, desde donde es posible entender al hombre como interlocutor de Dios en la historia. El autor acude al lenguaje como la mayor expresión del hombre, constatando en el sujeto humano una estructura semiótica como parte de su onticidad.

Palabras clave: Dios, Iglesia, antropología, semiótica, signo, experiencia, cristianismo.

* Conferencia de la Lectio Inauguralis de la Facultad de Teología de la Universidad Santo Tomás, 13 de febrero de 2013.

** Obispo de Neiva. Doctor en Teología de la Universidad Javeriana de Bogotá. Magister en Teología de la Pontificia Universidad Gregoriana de Roma. Especialización en docencia universitaria de la Universidad Santo Tomás. Correo electrónico: froi5@yahoo.es. 


\title{
On the way to a semiotic anthropology: theological reading of the sign
}

\begin{abstract}
:
In this article the author begins with a brief analysis of the phenomenon of postmodernism, as a collective existential that impacts the way of thinking of contemporary man. He supports his speech in semiotic anthropology, being the language and the sign an important significant for today's culture. From this code God has spoken to men and it is there precisely where it is possible to understand man as God's interlocutor in history. The author turns to language as man's greatest expression, confirming in the human being a semiotic structure as part of its onticity.
\end{abstract}

Keywords: God, Church, anthropology, semiotics, sign, experience, christianity.

\section{Introducción}

Parto de un problema: la crisis por la que pasa el mensaje cristiano. Solución: es crisis de SIGNIFICACIÓN. ¿Cómo el mensaje de Jesús impactó tanto en el Imperio Grecolatino?, ¿por qué ahora no? Ayer significó, hoy no. Se ha vuelto un jeroglífico en algunos ambientes culturales. No es crisis de contenido, es crisis de significación. ¿Por qué no resulta creíble el mensaje de Jesús hoy? Porque no se ofrece en clave de significación.

Por otra parte, se constata en la cultura hodierna un énfasis en la experiencia, en la dimensión sensible del hombre. El signo lo enmarcó en esta dimensión humana. Se ha pasado del axioma cartesiano: Pienso, luego existo, a la sentencia de la postmodernidad: Siento, luego existo. Analizaré brevemente el fenómeno de la postmodernidad, como un existenciario colectivo que incide en el modo de pensar del hombre contemporáneo. Constatamos en la cultura de hoy, una alta sensibilidad al signo y al signo que signifique. Por otra parte, en este código le ha hablado Dios al hombre. El hombre es el principal interlocutor de Dios, hasta el punto que Dios se hizo hombre.

De otro lado, al estudiar el lenguaje bíblico, evidencio que la metáfora en todas sus formas, es el modo más expedito de hablar del hagiógrafo. El mismo Jesucristo, nuestro único paradigma, emplea la parábola como la forma más familiar y coloquial para llegar a todos sus oyentes. Pareciera, siguiendo al filósofo 
alemán Jürgen Habermas, que el mensaje cristiano se hubiese helenizado. Se volvió más Atenas que Jerusalén: más $\Lambda$ ОГО $\Sigma=$ Logos = Razón; que anamnesis = Experiencia, vida, memoria-vida. Pareciera que se anunció más a Jesús con doctrinas que con la experiencia. El lenguaje con las escuelas griegas: Alejandría y Antioquía, tenía énfasis en la demostración antes que en la mostración. Jesús ha mandado que la distinción de los seguidores de Él no estaba en lo que enseñaban, sino en el modo de vida: En esto conocerán que ustedes son mis discípulos, si ustedes se aman (Jn 13, 35).

Quiero argumentar mi discurso en una antropología semiótica. Acudo al lenguaje como la mayor expresión del hombre, pues constato en el sujeto humano una estructura semiótica como parte de su onticidad. Los filósofos del lenguaje: Ferdinand de Sausurre (1979), Charles Sanders Peirce (1974) ${ }^{1}$, Émile Benveniste $(2001)^{2}$, John Austin (1989)3 , y John Rogers Searle ${ }^{4}$ así lo demuestran. No me puedo quedar en estos autores para argumentar la estructura semiótica del hombre, acudo también a San Agustín (1951-1957), quien presenta un exhaustivo análisis del signo. Como presupuesto de mi exposición, acudo al filósofo del lenguaje, más del metalenguaje, Paul Ricoeur (1980-1998-2001). Este pensador francés, muerto hace siete años (20 de mayo de 2005), me permite analizar el lenguaje bíblico que es eminentemente metalenguaje. La Biblia tiene una riqueza infinita en todos los géneros literarios de comunicación metafórica.

Durante el medioevo, en esa afortunada simbiosis filosofía-teología, leyendo a Aristóteles, doctores como Santo Tomás de Aquino (1952), argumentan la existencia de Dios a través de las conocidas cinco vías, y llevando el análisis a un énfasis racional. En la misma línea está San Buenaventura (1952), pero ya San Anselmo (1952), nos argumentaba con el llamado "argumento ontológico" la existencia de Dios. "Dios es un ser sin el cual nada puede pensarse".

Leyendo al gran teólogo jesuita alemán Karl Rahner, encuentro la respuesta al "status quaestionis". Es en el método antropológico trascendental que me

1 Estadounidense. Fundador de la semiótica moderna. Profesor en Harvard. Murió en 1914.

2 Francés. Profesor de la École Pratique des Hautes Études de Paris. Gran filósofo del lenguaje que lee a Sausurre. Murió en 1976.

3 Británico. Uno de los más influyentes representantes del "análisis del lenguaje corriente". El significado de una palabra será el enfoque central del estudio de los signos.

4 Norteamericano Profesor de la filosofía del lenguaje de la universidad de Berkely, Estados Unidos. Participó en el año 2000 en el diálogo ciencia-fe en el Vaticano, en el jubileo de los científicos. Este filósofo nació en Denver-Colorado en 1932. 
revela cómo el hombre es la mostración de Dios. Es en el hombre y desde el hombre en donde verifico a Dios, más como una experiencia que como un concepto demostrable. La lectura teológica del signo la hago desde este método, que me lleva a ver que el mensaje cristiano se verifica en el hombre. Es claro, el Hijo de Dios se hizo hombre. Rahner no parte de una mera especulación personal, él lo hace leyendo al jesuita Joseph Márechal (1959), quien ejercerá un poderoso influjo en el pensamiento rahneriano. Pero es que Márechal ve en Kant la apertura del hombre, leída en una línea horizontal; éste la lee en una línea trascendental, el hombre sale de sí, trascendiéndose.

Rahner igualmente lee a su maestro Martín Heidegger sobre todo en su obra El ser y el tiempo (1971). La tesis de grado de Rahner, Espíritu en el mundo, muestra el influjo de su maestro Heidegger, puesto que ve la apertura kantiana como doble apertura: categorial-finita y trascendental-infinita.

No quedándome con la mostración de Dios en el método antropológico trascendental, veo que la esencia del mensaje cristiano apunta a la mayor significación de Dios en el hombre: EL AMOR. Siguiendo al teólogo suizo Hans Urs von Balthasar (2006), sólo el amor es digno de fe. El anuncio del mensaje cristiano es el amor siguiendo a Jesucristo, y el amor en clave de significación. Nunca como ahora la imagen tiene tanto impacto, el hombre moderno sólo interactúa con un lenguaje que le signifique; un mensaje que se traduzca en la vida. Las experiencias de Teresa de Calcuta y Sor Emmanuelle, son la muestra del impacto que causa el amor.

El lenguaje del amor no exige un curso previo, así son los signos, llevan en sí un mismo lenguaje, una significación y un mensaje. La apertura trascendental se significa en el amor y éste es la manifestación más evidente de Dios. El amor por esencia es apertura, es la mayor significación de Dios en el hombre. El énfasis que da la postmodernidad a la dimensión sensible la traduce X. Zubiri (1980) como la "inteligencia sentiente", aquí de alguna manera refleja el enfoque actual de la primacía del sentir sobre el pensar. La modernidad ha endiosado a la razón, la postmodernidad es el “desencanto de la razón” (Casullo, 2004).

\section{La mediación de los signos}

Una de las funciones esenciales de los signos es la mediación. La interpretación de una realidad sensorial (función racional-humana), nos permite una función representativa (Benveniste, 2001). Aquí la representación, media la significación, que a su vez es significante y es significada (Saussure, 1979). Los signos que son 
la manifestación de la estructura semiótica del hombre, encuentran en el lenguaje el punto de llegada de su expresividad: la metáfora, que no es otra cosa que un lenguaje figurado, el camino más expedito para mediar su significación. La función mediática de los signos nos permite una interactuación, una especie de estímulo-respuesta (Skinner) que nos lleva a un permanente interrogar (Rahner, 1963). La mediación de los signos expresados en el ontos humano, nos lleva a una constante intercomunicación con los otros, trascendiéndolos hasta generar una relación con el Absoluto.

Es partiendo de la mediación como se llega al representado, en donde se encuentra que el hombre es mediación de Dios. La experiencia humana trasciende su propia expresión sensible, aquí es donde verificamos que el hombre es revelación de Dios. Cuando el signo pierde su función mediática, es decir, suplanta al representado, mutila la funcionalidad de la mediación. Cuando el hombre suplanta a Dios, cae en la peor alienación, impidiéndole ser sujeto de su propio desarrollo; cuando la creación suplanta al Creador se vuelve diabólica (Rm 1, 18ss).

El signo es la mediación más antropológica, es una relación, y se da gracias a la mediación de una interpretación, estando el código de esa interpretación en la misma naturaleza humana. En esa mediación aparece la significación (Eco, 2005)), que genera una respuesta del intérprete. La lectura del signo se hace en clave antropológica. El plan de Dios para el hombre, es ofrecido en lenguaje semiótico, es economía de mediación, ya que Dios le habla al hombre desde el hombre, pues es la única manera que éste entiende. No se conoce otra comunicación de Dios que no sea mediática, evidenciada en la encarnación del Hijo de Dios; esta es la columna vertebral de toda la historia de salvación. La mostración de Dios se evidencia y se significa en el hombre, quien lleva una impronta de Dios. Esa huella indeleble opera cuando se significa en una experiencia de amor, el otro, -sujeto humano- es significación de Dios, cuando por su apertura permite que Dios sea leído en su onticidad. Esta significación es dialógica, pues genera una relación personal que compromete en la vida y trasforma el entorno social. Los argumentos demostrativos ceden ante las experiencias significativas, y las doctrinas ofrecen un soporte argumentativo que fundamentan el actuar humano, como reza el axioma escolástico: "Operatiosequituresse". El hacer del hombre proviene de su ser; la mostración es la "operatiosequitur" que va más allá de los esquemas gnoseológicos, generando un compromiso con el otro y con el mundo. En modo alguno se pretende quitarle al hombre esa dimensión racional que le permite interrogar. En la capacidad de preguntar aparece la apertura al otro y al Absolutamente Otro (Rahner, 1963). 
En el enfoque de la antropología cristiana, el hombre es verdaderamente humano cuando es divino y es divino cuando es verdaderamente humano. De alguna manera tiene sentido que Israel no aceptó ninguna representación física de Dios, por el temor que la imagen-signo suplantara a Dios. Dios es uno solo. Sólo Dios hace libre al hombre, pues cuando depende de algo (culto a la naturaleza) o de alguien (culto al yo personal o colectivo), no es libre, se torna esclavo de las cosas o de las personas. Con razón decía el autor sagrado: “Maldito el hombre que se fía del hombre, y hace de la carne su apoyo" (Jr 17, 5). Todo endiosamiento aliena al hombre (Habermas, 2001). El finito, cuando se arroga la identidad de infinito, esclaviza y oprime al otro.

El símbolo es la mediación necesaria de la autorrealización del ente (Rahner, Escritos de teología, 2002). Al ser el hombre significación de Dios, resulta ser mediación de Dios; esta mediación es análoga, no suplanta a Cristo "único mediador entre Dios y los hombres" (1 Tm 1,5). De ahí que Cristo es el único paradigma del hombre.

\subsection{La cultura postmoderna en clave semiótica}

La postmodernidad está marcada por la cultura de la imagen, la "Razón Ilustrada" no ha satisfecho las inquietudes humanas y no ha dado respuesta al sentido de la vida. La diosa Razón entronizada en el pináculo del conocimiento, no responde al hombre situado en la miseria, la soledad y la incomprensión. Se puede decir que la modernidad no dio la talla a los anhelos del hombre. Leer la cultura postmoderna desde el horizonte hermenéutico de la teología y desde la epistemología del signo, resulta un camino expedito en la búsqueda de respuesta a la crisis del mensaje cristiano hoy. Las consecuencias políticas, económicas y sociales de la postmodernidad, generan una mentalidad "light" =ligera, superficial, en donde se acaba la solidez de los principios, dando cause a un relativismo total en materia moral y por ende política. Asistimos a un "cambio de época" (DA No. 44), el hombre de esta época desconcierta y da giros copernicanos en su conducta, consecuencia del relativismo moral reinante.

Si el hombre moderno de alguna manera absolutizó la razón como instrumento de conocimiento, el postmoderno sostiene que "el conocimiento también nos llega por el sentido común y por el inconsciente, por la intuición, la imaginación, la afectividad, la imagen, el signo y el mito, e incluso por ciertas experiencias místicas y por ciertas dotes parasicológicas" (Correa, 2000). La naturaleza del signo lingüístico y paralingüístico responden a esta cultura, el conocimiento 
de Dios se ve por el camino de la mostración y de la experiencia. El hombre es la mayor significación de Dios, y por medio dela antropología del signo se visualiza esta experiencia; una sana lectura del postmodernismo impulsará la mostración de Dios en el hombre. Por otra parte, el lenguaje bíblico va más por la línea de la imagen que de los conceptos.

El hombre de ciencia moderno pretendía la objetividad mediante el método analítico y experimental, mientras que el hombre postmoderno aprecia métodos más holísticos, capaces de aproximarse a la realidad concebida como una totalidad, que reclama ser conocida desde dentro y mediante datos de preferencia cualitativos. Métodos que no se conforman con la explicación de los fenómenos, sino que apuntan a la comprensión de los mismos, comprensión que se lee en clave de experiencia más que de raciocinio.

Desde el punto de vista del hombre moderno, la naturaleza es un medio de subsistencia, de explotación y de enriquecimiento; el postmoderno, va descubriendo cada vez más el valor del equilibrio ecológico como espacio vital e interrelacional, para desarrollarse como persona. El hombre como "ser en el mundo", se descubre de forma espacio-temporal y consecuentemente protege su medio vital, como experiencia que trasciende su propio "estar ahí".

Sólo dos vías de organización social eran aceptadas por el hombre moderno solo aceptaba, el capitalismo y el colectivismo; el postmoderno, "proclama como antídoto un personalismo y comunitarismo, que serían la contrarréplica a ambas utopías modernas. Algunos, sin embargo, podrían mirar estos últimos no producidos por la postmodernidad sino paralelos a ella" (Vélez Correa: 2000, 32). En la cultura de la modernidad, el hombre ha resultado huésped en su propia casa; la ciudad ha resultado agresiva dificultando la convivencia humana; el hombre postmoderno quiere sentirse persona, ser reconocido y valorado. En este ambiente entra más fácilmente el mensaje cristiano. La cultura postmoderna es una fortaleza para anunciar la Buena Nueva de Jesucristo.

El hombre moderno proponía una organización social, cultural y religiosa basada en una rigurosa racionalidad; la postmodernidad se manifiesta ecléctica y pragmática en materia religiosa (Correa, 2000). El relativismo moral campea en todos los escenarios de la cultura postmoderna, mientras que el patrón cultural es el relativismo religioso y político. La muerte de Dios de los "maestros de la sospecha" (Ricoeur, 2000) parece un dato histórico, pues el despertar religioso es ya evidente y presenta visos de fanatismo en algunos lugares del planeta.

En la obra, Megatendencias de dos escritores norteamericanos (Naisbit \& Aburdene, 1990), aparece "el despertar religioso" del tercer milenio, como una de las diez megatendencias que caracterizan al tercer milenio, no cabe duda que 
está resultando una realidad. Es contradictoria la cultura de hoy en términos religiosos, pues, si por una parte aparece el agnosticismo, por otra, las religiones de corte riguroso y fundamentalista como algunas vertientes del Islam, han crecido de forma alarmante, por ejemplo en Europa y América, los movimientos religiosos de enfoque fundamentalista abundan a granel. Pareciera, entonces que el "desencanto de la Razón ilustrada" puede desembocar en una religiosidad de tipo fundamentalista e integrista, que se ha venido introduciendo en los ámbitos de la Iglesia Católica. Ordinariamente una polarización lleva a la otra, causando, con frecuencia, consecuencias nefastas.

Definitivamente la diosa Razón no satisface al hombre: ni el positivismo de Augusto Compte, ni el neopositivismo de L. Wittgenstein, llenan las expectativas humanas; Jean François Lyotard habla de un tiempo postmoderno: plural, policémico, parcial en valores, habla sin sentidos (Lyotard). Nada es estable en la cultura postmoderna; lo que hoy es un valor, mañana puede no serlo, resulta paradoxal la situación, pues el hombre se siente inseguro y busca seguridad en el primer movimiento religioso que lo "toque", generando una dependencia del predicador de turno, hasta llegar a la adición del mensaje y de quien lo "orienta". Aparece una espiritualidad narcótica que neutraliza sus anhelos espirituales, causándole una especie de sueño espiritual.

En el occidente de "cultura cristiana" encontramos una contradicción: por una parte se rechaza toda manifestación externa de la Iglesia, cualquier símbolo que exprese alguna creencia cristiana. Se esgrime a voz en cuello la libertad de conciencia y la defensa al derecho a la propia autorrealización, pero al mismo tiempo se es absolutamente condescendiente y respetuoso con toda otra forma de expresiones religiosas, con tal de que no sean las de la Iglesia Católica. Aquí se pueden hacer todas las burlas a los símbolos religiosos de la Iglesia, pero eso sí, se respetan a los que vengan de fuera, ¡que paradoja!

A la religión le han salido competidores en la función social, parece que cada vez se ve a la Iglesia como una ONG más que como a una comunidad profética, que anuncia salvación y denuncia toda forma de pecado. Como dicen los sociólogos de la religión: las ideologías totalitarias pueden hacer las veces de religión borrando de tajo toda relación trascendente. La religión en esta economía global es una oferta más, el "mercado persa" de ofertas religiosas fortalece el departamento de mercadeo, poco importa el contenido, lo importante es su presentación; la postmodernidad quiere los resultados a corto plazo. Las estrategias religiosas que toquen el sentimiento, obtienen utilidades inmediatas, a su vez esas ofertas son, en lenguaje bíblico, "nubes mañaneras" que así como aparecen, 
desaparecen. El hombre en este contexto termina por ser volátil, lo relativiza todo y vive el presente, sin conexión con ningún pasado.

Podemos calificar la sociedad postmoderna, como la sociedad de la racionalidad funcional. Aparece entonces la ley del rendimiento y la eficacia, con diferentes "esferas de valor", lo que significa que el relativismo moral es su carta de presentación a esta cultura se debe presentar el mensaje cristiano en clave de significación, para que la buena noticia responda a los anhelos y esperanzas del hombre necesitado de salvación. La sensibilidad de esta cultura a la imagen, al signo, favorece la presentación del Evangelio.

\section{2 ¿Helenización del cristianismo?}

En este acápite quiero valerme de las críticas del teólogo-historiador luterano Adolf Von Harnack (1904) y del filósofo, también alemán, Jünger Habernas (2001). Harnack nos hace ver, en la esencia del cristianismo, que el mensaje de Jesús perdió su originalidad al abrirse a la cultura griega y latina, pero al mismo tiempo afirma: "por mucho que progrese la civilización, por mucho que se extiendan las conquistas del entendimiento humano, jamás será superada la sublimidad moral del cristianismo" (Harnack, 1904). ¿De dónde los complejos de inferioridad hoy? El mensaje del Evangelio apunta a la esencia del hombre: el amor, que jamás pasará de moda, es más, lo único que permanece es el amor (1 Co 13,13); el mundo es de quien sabe amarlo.

El amor entra en conflicto con el desamor, es decir, con todo lo que afecta negativamente al hombre. El amor fue llevado a la cruz por el no amor, pero finalmente el primero triunfó. Cuando el mensaje cristiano pierde su norte, los hombres de cada cultura no descubren a Dios, y el mundo de hoy tiene sed de Él; y cuando no lo encuentran en la vida, crean sus dioses, que al mismo tiempo, resultarán sus propios verdugos. El sermón de la montaña es la quintaesencia del Evangelio, y en estos tres capítulos se nos presenta el vademécum de la vida cristiana; el hombre es centro de Dios. La antigua alianza se refleja en el "habéis oído que se dijo a los antepasados", la letra de la ley; "pues yo os digo" es la nueva alianza, lo que cuenta es el espíritu de la Ley, no centrada en la norma sino en la persona de Jesucristo (Mt 5-7). Es que "sólo el amor es digno de fe", la doctrina que no se muestra en el amor, no es digna de fe. Decía el gran Agustín de Hipona: "vuelve sobre ti mismo. La verdad habita en el hombre interior. Y si encuentras que tu naturaleza es mutable, trasciéndete a ti mismo. Pero recuerda que al hacerlo así, trasciendes un alma que razona. Así pues, dirígete a allí, donde se enciende la luz de la misma razón" (Hipona: 1951, 3972). 
“El amor al prójimo en la tierra es la única manifestación real del amor de Dios que vive en la humildad" (Hipona, 1951). Los primeros cristianos entendieron que la predicación de la Palabra-doctrina, se hacía experiencia en la Koıvovı $\alpha=$ Comunidad-comunión. Sólo así impactó la fe cristiana en el mundo pagano; habría que analizar que si el intento loable, por cierto, de las escuelas de Alejandría y Antioquía por dialogar con la cultura vigente, la griega, pusieron el énfasis en los conceptos más que en las experiencias.

En el simposio que se realizó en Münster el 16 de junio de 1993 con ocasión del acto de investidura de Johan Baptist Metz como profesor emérito, Habernas se pregunta ¿a quién pertenece la razón anamnética? Según Habernas, Metz responde que Atenas perdió el encantamiento de la memoria de la cultura semita; se trata ahora de enlazar la razón comunicativa con la razón anamnética. Comentando a Metz, Habernas agrega: “a través de la razón filosófica de procedencia griega, un cristianismo helenizado se ha dejado distanciar, tanto en sus propios orígenes en el espíritu de Israel, que la teología se ha vuelto insensible, frente al grito del sufrimiento y frente a la demanda de la justicia universal" (Habermas, 2001).

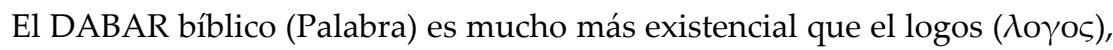
el primero, explica; y el segundo, convoca a un compromiso. El Logos va en una línea de conocimiento; mientras que el Dabar, en un compromiso personal. El Logos, va convirtiendo el mensaje cristiano en un sistema intelectual; es más atento a la noción de verdad que al de "Buena Noticia" (Faus, 2006). Con este "horizonte hermenéutico", el mensaje de Jesús se hizo más "depósito de fe" que experiencia de vida, y la teología se hizo más apofántica que soteriológica.

Jon Sobrino (Faus, 2006) nos dice que conviene cambiar el esquema del clásico intellectusfidei, por el intellectusamoris. Toda la cultura griega parece girar en torno a una primacía de la razón sobre la experiencia. En los padres latinos, el influjo de Platón sobre Agustín es evidente, en Santo Tomás es claro el influjo de Aristóteles; en sí, esto no es un error, sino que obedece a la inculturación del Evangelio. No cabe duda que el aporte de la filosofía griega al pensamiento cristiano, le trajo un avance en el conocimiento. La inculturación del Evangelio hoy, exige una lectura de la "racionalidad emergente" del signo.

\section{El metalenguaje como manifestación de la estructura semiótica del hombre}

Para Paul Ricoeur, el lenguaje es una mediación entre el hombre y el mundo; el metalenguaje es el vehículo que facilita la relación del hombre con su entorno. 
En todas las culturas, y si son más antiguas, el fenómeno es mucho mayor. Los diferentes géneros literarios aparecen como la expresión espiritual de un pueblo, los tropos resultan los instrumentos más asequibles para expresar sus sentimientos. El paralenguaje para Israel, y para todos los pueblos de la tierra, reflejan con mayor intensidad los sentimientos de un pueblo.

El metalenguaje apunta más al sentir que al pensar, por el contrario el lenguaje, sobre todo el escrito, expresa más la racionalidad humana, va más en la línea de los conceptos, de las abstracciones. De ahí que el hombre en los albores de su existencia empieza comunicándose con el metalenguaje. El lenguaje tropológico es propio de la oralidad, la cual es más experiencia-vida que concepto. El lenguaje poético, propio de la cultura oriental, es polisémico y metafórico (Ricoeur, De la interpretación del signo a la interpretación del texto, 2000). La cultura hodierna, occidental, las sagas de Harry Potter y los secretos de Narnia, tienen mucha acogida en el público, porque son más signo que concepto.

\subsection{El metalenguaje en la Biblia}

Al abordar el metalenguaje bíblico constatamos la trazabilidad semiótica de la apertura humana. La cuestión de Dios es cuestión del hombre (Alfaro, 1988). El lenguaje bíblico es el lugar teológico más antropológico para ver la estructura semiótica del hombre.

¿Qué son los géneros literarios? (Ricoeur, Tiempo y narración, 1988). Es la manera de escribir de una época o región, para expresar lo que se intenta decir. Los géneros literarios son las expresiones propias de una cultura, para comunicar los pensamientos y sentimientos, y resultan el camino más expedito para manifestar el alma de un pueblo. Siguiendo el número 12 de la Dei Verbum, el lenguaje bíblico se enmarca en la cultura; la escritura contiene el mensaje divino en código humano.

El Talmud (comentarios hechos por los estudiosos de la Torad), recoge las discusiones rabínicas sobre leyes judías, tradiciones, costumbres, leyendas e historias. El Midrash, que significa explicación, indica la exégesis que se le hace a la Torad facilitando su comprensión. El signo lingüístico es interpretado aquí en el contexto de una cultura.

La parábola, que viene del griego $\Pi \alpha \varrho \alpha \beta o \lambda \varepsilon 0=$ comparar, es un género literario en el Antiguo Testamento pero más frecuente en el Nuevo; es un género sencillo captable por todos, habla de la vida y es un vivo ejemplo del mensaje cristiano. Este último no está en crisis, pero su significación sí, y lo que no tiene significado para el hombre postmoderno, no es objeto de su interés. Una iglesia 
sencilla y acogedora se vuelve fascinante y atractiva (Quasten, 1984)), y el Evangelio encarnado se hace fascinante por la experiencia de vida.

\subsection{La mostración de Dios}

La teología, que es una ciencia humanística, está centrada en el hombre como apertura a Dios, pues sin antropología no se puede hacer teología (Rahner, Curso fundamental sobre la fe, 2007), esto es parte de la observación del hombre como experiencia de Dios. Hacer teología es hablar de Dios desde el hombre, Dios se hizo hombre, y el hombre es un ser referido a Dios (Rahner, Curso fundamental sobre la fe, 2007) ${ }^{5}$. Se hace entonces teología, observando al hombre. En las ciencias naturales descomponemos un elemento y le descubrimos su valor atómico o molecular, lo que se demuestra es propiedad del conocimiento y además, es superable para seguir conociendo. Si Dios fuese objeto de demostración, su conocimiento lo hubiese superado; a Dios no se le puede reducir a un tubo de ensayo, Él es más que demostración, es mostración. Dios es "verificable" cuando el hombre lo significa.

Para mostrar a Dios en el hombre, acudo a la epistemología del método antropológico trascendental de Karl Rahner (1967-1963-2007). Este teólogo alemán construye su pensamiento, valiéndose de la metafísica del conocimiento finito según Santo Tomás, (1952 Suma teológica I Texto de la cuestión 84. Art. 7. 23), a su vez, Rahner, se fundamenta en Joseph Marechal (1959): En la crítica de la razón pura, Kant, aborda la analítica trascendental (Márechal, 1959), Marechal lo lleva a Kant. Rahner a su vez recibe el influjo de su maestro, el agnóstico Martin Heidegger $(1971,17)$, quien nació en una familia católica. La apertura constatada por Heidegger, en el hombre en línea horizontal, Rahner la lee en clave trascendental; Heidegger dice que: "este ente que somos cada uno de nosotros mismos y que tiene entre otros rasgos la 'posibilidad de ser', del preguntar, lo designamos con el término dasein (ser ahí)" (Heidegger: 1971, 17). "Ser ahí", para Heidegger es ser en el mundo; "ser ahí" muestra la temporalidad del ente, abierto en su propio "ser ahí".

Esto quiere decir que el hombre se descubre a sí mismo en el espacio y en el tiempo. Esa apertura apriórica constatada por Heidegger, es leída por Rahner como doble apertura, a saber, categorial (finita, espacio-temporal) constatada por el hombre como "espíritu en el mundo". La segunda apertura, consecuencia de

5 Aquí teología y antropología se hacen necesariamente una sola cosa. 
la primera, es la trascendental (infinita y que en el excesus se descubre como trascendental $)^{6}$. En las Meditaciones sobre los Ejercicios de San Ignacio, dice nuestro teólogo: "trascenderse a sí mismo es abrirse a la inmediatez de Dios", observando al hombre descubrimos en él la experiencia de Dios. La expresión más antropológica del Antiguo Testamento es "Emmanuel", Dios con nosotros $($ Is 7,14$)$.

\subsection{La cuestión de Dios}

El hombre es un permanente "preguntar", se pregunta por el sentido del ser (Rahner, Espíritu en el mundo, 1963)), en el fondo de la pregunta está el sentido de su existencia, que no se conforma con la mera temporalidad. Por ser espíritu en el mundo el hombre pregunta, y al preguntar aparece como un ser insaciable; su insaciabilidad es expresión de su trascendencia, tiene necesidad de absoluto y no se satisface a sí mismo. San Agustín expresa su experiencia de la necesidad de buscar a Dios, como única respuesta a su sed de infinito. El Santo Doctor busca a Dios en los filósofos de su tiempo, en los maniqueos y finalmente lo descubre en sí mismo: “'Sero te amavi, pulchritudotamantiqua ettam nova, sero te amavi!” - “¡Tarde te amé, hermosura tan antigua y tan nueva, tarde te amé!” (Agustín, 1951a). Continúa San Agustín: "Et ecceintus eras ego foris et ibi te quaerebam et in istaformos, quaefecisti, deformisirrubam" - "Y he aquí que tú estabas dentro de mí y yo fuera, y por fuera te buscaba". "Mecum eras, et tecum no eran" - "Tú estabas conmigo mas yo no estaba contigo".

El hombre en su propia estructura óntica es potencia, es decir, posibilidad de revelación de Dios (Rahner, Oyente de la palabra. Fundamentos para una filosofía de la religión, 1967) ); el hombre es el único interlocutor de Dios, ya que es su "imagen y semejanza". Una relación personal sólo se da entre personas, por ello no puede haber una relación personal con la naturaleza, si bien es cierto que la naturaleza es un lugar de la Revelación de Dios, también es reflejo de Dios. Así pues, el salmista puede exclamar: "los cielos proclaman las gloria de Dios" (Sal, 18). El hombre, al relacionarse con la naturaleza, se siente administrador de la misma, pero no puede entablar con ella una interlocución. Con razón, los Padres del Vaticano II afirmaron que el misterio del hombre se esclarece en el misterio de Cristo hecho hombre (Gaudium et spes n. 22).

6 Esta es una de las tesis de Rahner que va desarrollando en sus obras: Espíritu en el mundo, Oyente de la palabra y Curso fundamental sobre la fe. 
Si el hombre ha rechazado a Dios es porque le han formado una idea falsa de Él o, con la vida de los "defensores de Dios" demuestran su inexistencia. El mito de Prometeo que le roba el fuego a los dioses para entregárselo a los hombres, es una muestra de que el dios creado por su cultura mutila al hombre. En tal contexto es "comprensible" la "muerte" de Dios. Es llamativo que los "maestros de la sospecha" (Ricoeur, Conflicto de las interpretaciones, 1998a) ${ }^{7}($ los tres pertenecieron a familias pietistas de corte protestante), negaron la existencia de Dios. Si alguien impide el libre desarrollo del hombre, así ese "alguien" se llame dios, el hombre se rebela, pues va contra su propia existencia; nadie acepta, y menos aún, ama al que le hace daño. De ahí que el ateísmo de muchos es comprensible, nunca aceptable. La Palabra de Dios valora tanto al hombre que además de ser "imagen y semejanza" de Dios, lo creo "poco inferior a los ángeles" (Sal, 8). La corona de la grandeza del hombre, está en la Encarnación de Dios; decía Edwar Schillebeeckx, "la fe en Dios es imposible sin el hombre" (Schillebeeckx, 1995).

En el hombre está "la anticipación" del "esse", que es anticipación del Infinito. Rahner siguiendo a Santo Tomás, encuentra en el hombre, como ser abierto, el intellectusagens que es la estructura apriórica del espíritu como anticipación de excesus (salida) al "esse" o sea, a Dios. El hombre, al ser anticipación de Dios, está mostrando a Dios, y esta mostración resultaría en todas formas aprióricas de la sensibilidad, y de las formas aprióricas del espíritu dadas en anticipación (Vorgriff) que se unen en la conversio abstractiva ad phantasma (apariencia). Esta última es la abstracción de la realidad sensible, superándola al asumirla. No se trata de una negación de la realidad sensible, "ser en el mundo", sino de asumir la realidad del mundo, "siendo mundo" con una apertura trascendental.

La experiencia trascendental del excesus, salir de sí, es la experiencia de la trascendencia (Rahner, Curso fundamental sobre la fe, 2007)), y la experiencia de la trascendencia en el hombre (ser en el mundo), es trascendencia del amor, el cual es la verificación de la trascendencia del hombre "ser en el mundo". El hombre en cuanto experimenta radicalmente su finitud, llega más allá de ella, se experimenta como ser que trasciende como espíritu; la finitud le permite descubrir su sed de infinitud. La trascendencia muestra que el hombre es un ser referido a Dios (Rahner, Curso fundamental sobre la fe, 2007). Y por estar referido, el conocimiento de Dios es conocimiento trascendental. El dónde y el hacia dónde de la trascendencia se llama Dios. El ateísmo y el teísmo vulgar, son contrarios

7 Así llamó Paul Ricoeur a Marx, Freud y Nietzsche, los tres grandes ateos del siglo XIX-XX. 
al hombre "espíritu en el mundo", ambos sufren de una representación falsa de Dios, con la diferencia de que uno la rechaza, mientras que el otro cree poderla pensar (Rahner, Oyente de la palabra. Fundamentos para una filosofía de la religión, 1967). El ateísmo es contrario al ontos humano, y la trascendencia del hombre no es un agregado a su naturaleza, pertenece a su ipsisidad.

El hombre como "ser en el mundo" existe en el "aquí", relación espaciotemporal. El aquí y el ahora en el hombre exige una apertura a los otros, nada más alienante que "huir" del mundo. Es en el mundo donde el seguidor de Cristo es signo del amor de Dios. El hombre "terreno" en antropología paulina, es el hombre centrado en sí mismo, cerrado a los demás, en donde no cabe la experiencia de Dios, porque su yo narciso no le permite salir de sí para encontrarse con los otros. El hombre "celestial", por el contrario, es el hombre abierto, pues la apertura a Dios les exige una apertura a los otros. El hombre es la revelación de Dios en lo singular, esto es, en lo categorial.

El materialismo histórico, cuando pretendió cortarle al hombre su relación trascendente, lo mutiló, porque quitarle al hombre su dimensión trascendente, es quitarle su alma, es animalizarlo. La construcción de la historia al margen de Dios, es la destrucción del hombre; las guerras y la ambición de poder, están respaldadas por la negación de Dios y la absolutización del hombre. Saquemos a Dios del corazón del hombre y tendremos una sociedad de monstruos. La apertura trascendental desarrollada, respetando la estructura humana, hace al hombre no solamente libre, sino también liberado de su egoísmo y abierto por la trascendencia a los otros.

Sólo se es cristiano cuando se es perfectamente humano. Dios no ha querido construir su plan de amor al margen del hombre, sino que al crearlo ha querido participarle de su naturaleza. De ahí, como he venido afirmando, si quieres buscar a Dios descúbrelo en el hombre. El código de esta lectura no pone el énfasis en la demostración de Dios, sino en su mostración ,ésta tiene una connotación, es una clave de significación; pero no es una mera mostración óntica, sino una mostración semiótica. No se trata de tomar el signo frío y conceptual, sino el signo significante, es decir, que interactúa, que exige ser leído y consecuentemente genera una respuesta. La significación de Dios en el hombre, no puede dejar al lector del signo en actitud pasiva; la significación lleva consigo una respuesta que compromete la vida.

La gracia no destruye la naturaleza, nos decía Santo Tomás, y como decía San Anselmo de Canterbury: "Fidessupponitrationemsicut gratia natura" - "la fe supone la razón, como la gracia supone la naturaleza" (Alfaro, 1988). La fe no es un agregado a la naturaleza humana, es la respuesta a su natural apertura 
trascendental, es un don, una gracia; pero al mismo tiempo, toda la naturaleza humana es gracia de Dios, todo es don gratuito de Dios.

La mostración, hemos dicho, se lee en clave de significación, sólo significa lo que tiene sentido para mí, es el énfasis del hombre postmoderno. Al leer al hombre encontramos que no lleva en sí mismo el fundamento último de su ser, sino que se muestra como fundado más allá y fuera de sí mismo: abierto a algo que trasciende (Alfaro, 1988).

No se trata entonces de la esencia constitutiva del hombre, sino de su existencia. La mostración toca más el sentido de la vida que la razón de la misma, interpretando a Kant, la cuestión de Dios es una exigencia de la razón práctica, no es por vía demostrativa que se constata a Dios en el hombre, es por vía mostrativa. En general, los ateos teóricos de los siglos XIX y XX negaron la existencia de Dios, por no significar nada para el hombre (Alfaro, 1988). Es más, algunos de ellos vieron a Dios como el obstáculo a la realización del hombre. El Dios de la revelación ha mostrado, y es tan evidente su manifestación, que se ha "encarnado", "Ha puesto su tienda entre nosotros" como manifestación de su amor (Jn, 3, 6).

\subsection{El amor, verificación de la mostración de Dios}

El amor es la esencia existencial del hombre, es como el "ser ahí" del hombre, es la más evidente mostración de Dios, es una mostración atrayente y fascinante que contagia el ambiente. El amor no deja al hombre impasible, es más, lo cambia radicalmente, dándole sentido a su existencia. Toda la Palabra de Dios y su experiencia viva en la Tradición de la Iglesia, no es otra que, trasmisión de amor, cuando el hombre racionaliza exclusivamente esa Palabra, la hace abstracta e inocua a la historia humana. En este sentido, se trata de leer el mensaje divino en su sentido original, pues la única característica por la que identificarán a los cristianos es el amor (Jn, 13,35). "Sólo el amor es digno de fe" (Balthasar, 2006).

La fe tiene que "mostrar" su credibilidad a través del amor, porque genera una respuesta cuando es significativo. En el discurso que he venido desarrollando, he expuesto que cuando el hombre expresa su razón de ser: el amor, evidencia a Dios El "Absolutamente otro", de R. Otto (1965), se hace "Dios, amor que desciende" (Rahner, Dios, amor que desciende, (Escritos espirituales), 2008) y "misterio fascinante y tremendo" (Otto: 1965). Ya el hagiógrafo del AT anunciaba un "Dios con nosotros" (Is 7,14); el Dios "misterioso y tremendo" del Sinaí, "ha puesto su tienda entre nosotros" (Jn 1,14). Pareciera que el hombre religioso no 
quiere aceptar la Encarnación de Dios, pues tal vez no le deja hacer al hombre sus caprichos egoístas y mezquinos. El dios alegado de las religiones, le resulta más cómodo al hombre, pues no interviene en su historia y así puede hacer un "dios" a su "imagen y semejanza", que todo lo justifica, es más, "bendice" sus caprichos egoístas.

Cuando el "dios" de las religiones "decide visitar" a los hombres, es para complacerlos en sus instintos pasionales: la vida, -todas las diosas de la fertilidad-; el sexo, -todos los dioses de la sexualidad-, la venganza frente a los enemigos, etc. Si analizamos, por ejemplo el panteón romano, el egipcio y el griego, encontramos la misma constante; y la experiencia de las religiones mistéricas prueban éste fenómeno cultural, que por ende, es antropológico. Esta "inmanencia" de los dioses, no es otra cosa que una complacencia de los mismos en la ciudad de los hombres. En la mitología griega la ciudad de Argos es el "balneario" de los dioses, empezando por Zeus, allí complace a los hombres compartiendo sus propios instintos egoístas. ¡Que diferencia del Dios encarnado en Cristo!, que exige un compromiso siendo el hombre gestor de su propio desarrollo. El Dios encarnado en Jesús de Nazaret no mutila al hombre, lo hace verdaderamente humano.

\section{Cristo, único paradigma de la significación de Dios}

La persona de Jesús ha suscitado interés a lo largo de todos los tiempos, ninguno como Él ha suscitado tanta controversia, es un hombre incomparable y al mismo tiempo tan cercano, hace "Kénosis" (Fil 2,6-11). Jesús rompió todos los esquemas, nos dicen los evangelios que la gente quedaba "confundida", no había de qué acusarle. La absoluta trasparencia de Jesús no fue "soportada" por la maldad de los hombres, su presencia no encontró "lugar" en la ciudad de los hombres, "no hubo sitio en la posada" (Lc 2,7).

Tal es la mezquindad humana, es que el hombre es un ser paradoxal, tan grande y tan pequeño a la vez. Grande por Dios, pequeño por su pecado. No sé si resulto un tanto pesimista, pero lo único que ha hecho el hombre de su propia autoría, es "el pecado" (Gn, 3). Los relatos del juicio de Jesús muestran la "pobreza" humana y la grandeza del hombre Jesús (Lc, 22-23 y paralelos). Afirmo que el hombre es un ser paradoxal, porque como dice San Pablo, está llamado a hacer el bien y sin embargo hace el mal (Rm, 7,15 y 2 Co,r 12,7-10). ¡Ah! El hombre es un ser tan grande y tan pequeño a la vez. 


\section{La Iglesia: lugar del amor a dios y al hombre}

El mensaje cristiano es creíble, así aparece en el desarrollo de este escrito. El problema mayúsculo es la Iglesia; aunque ella en sí no es problema, es su falta de credibilidad al presentar el mensaje de Jesús. Si la Iglesia es "Sacramento de salvación" (LG, 1), tiene que hacer creíble el Evangelio significándolo en la vida.

La Iglesia, comunidad que tiene a Cristo por cabeza y fundamento, está llamada a ser siempre "sacramento" del amor de Dios; con razón el Papa Pio XII llamó a la Iglesia "Cuerpo místico" de Cristo (Encíclica, Mystici Corporis, 21 de junio de 1943). La Iglesia está en el mundo para mostrar el amor de Dios, y ese amor se visualiza en la comunidad. El Concilio Vaticano II, lamenta que la división de los cristianos es uno de los mayores escándalos ante los no cristianos ${ }^{8}$, Taize es una muestra del deseo de unidad que buscan los cristianos, el signo de esta comunidad es una invitación a buscar la unidad bajo la misma fe, para hacer creíble el mensaje de Jesús.

La soberbia de las iglesias es la principal causa que ha impedido la comunión. Si todos no nos ponemos bajo el cayado de Jesús abiertos al Espíritu Santo, no mostraremos a Jesús (Congar, 1961), no basta anunciar el Evangelio, hay que hacerlo creíble, y su credibilidad se hará visible cuando los cristianos seamos "sacramentos", signos de Jesús. No hay otro camino de ser signo de Jesús, que viviendo en comunión.

El parto de la Iglesia se experimenta en comunidad (Hch, 2,13), los apóstoles estaban reunidos (comunidad) en oración, cuando experimentaron la "fuerza de lo alto". Se "abrieron" las puertas; aparece allí una metamorfosis. De cobardes, se tornan valientes; de huir cobardemente, se lanzan a la plaza pública a testimoniar, asumiendo todos los riesgos, ¿Cómo se entiende que de las "puertas cerradas" ahora salgan a la plaza pública? El vivir en comunidad lo testimonia.

El hombre moderno, tan sensible a los signos, se "convencerá" del mensaje de Jesús cuando lo visualice en los cristianos. En palabras del Apóstol: los cristianos estamos llamados a ser "olor de Cristo", tanto para los que se salvan como para los que se pierden (2 Co 2,14-15); los cristianos estamos llamados a ser "luz" y "sal" de la tierra. El vademécum de los cristianos es el Sermón del Monte, y el meollo del mismo es el primer capítulo de esa trilogía capitular (5-7) en donde nos llama el Maestro a ser "luz" y "sal".

8 Decreto sobre el Ecumenismo y sobre la Actividad misionera de la Iglesia. 
Lo que confundió la mezquindad de los paganos, fue el "modo de vida" que llevaban los cristianos (Quasten, 1984) ${ }^{9}$. El mundo es de quien lo ama y sabe demostrarlo (Thuan, 2000). El hermano Roger Schütz (2001) cuando comenzó su comunidad en Taizé, en 1940, se propuso "mostrar" a los cristianos que la división es lo más contrario al Evangelio, y surgió esta reflexión: hemos luchado durante siglos demostrando quien tiene la "verdad". ¿Por qué no buscamos el camino del amor para llegar a la verdad? ¡Que experiencia! Hoy llegan a Taizé por la estación estival, alrededor de 10000 personas, un $80 \%$ de ellas son jóvenes; ¿a qué llegan? A orar porque Cristo los une. Todavía hay gente tan pesimista que cree que el mensaje cristiano no tiene novedad hoy, y es triste ver a muchos cristianos como pordioseros en el mundo, cuando están pisando una mina de diamantes.

¿Por qué la Madre Teresa de Calcuta impactaba? Porque daba amor. El mundo no está alejado de Dios, es que no ha descubierto el amor, el signo de Jesús que atrae, es el amor. Ante un mundo indiferente y cada vez más alejado de la Iglesia, los cristianos estamos llamados a ser el Evangelio Encarnado en el mundo. ¿Por qué tantos se alejan de la Iglesia?, ¿será que muchos cristianos no son signos? Un signo que no signifique no impacta, y consecuentemente no genera interactuación; tal vez en la Iglesia hay muchos signos, pero muchos de ellos son jeroglíficos. ¿Por qué impactó tanto Sor Emmanuelle? Porque amó.

Omniavincit amor, dice Virgilio en las Bucólicas: “¡Todo lo vence el amor!”, y añade: "Et nos cedamusamori", "rindámonos también nosotros al amor". El amor es el que prepara el camino al Evangelio, mejor aún, el Evangelio es el amor. En un mundo lleno de soledad, en donde los hombres no son reconocidos personalmente, son seriados, codificados; hay más urgencia de amor. El hombre de hoy ha resultado huésped en la ciudad de los hombres, es entonces cuando resulta mucho más sensible al amor. Cada cristiano debe decir con Teresa de Lisieux: "en el corazón de la Iglesia, mi madre, yo seré el amor". El cristiano mostrará el amor haciendo iglesia, es decir, construyendo la comunidad.

9 El mensaje cristiano no se "impuso" por la fuerza de la organización, por la magnificencia de las construcciones, sino por la fuerza del amor. 


\section{Referencias}

Agustín, S. (1951a). Las confesiones. En S. Agustín, Obras completas (pág. 38). Madrid: BAC.

Alfaro, J. (1988). De la cuestión del hombre a la cuestión de Dios. Salamanca: Sígueme.

Anselmo, S. (1952). Proslogión. En S. Anselmo, Obras completas. Madrid: BAC.

Aquino, S. T. (1952). Suma contra gentiles. Edición en dos volúmenes, I libros 1 y 2. Madrid: BAC.

Aquino, S. T. (s.f.). Texto de la cuestión 84. En Suma Teológica I.

Austin, J. (1989). Ensayos filosóficos. Madrid: Alianza.

Balthasar, H. U. (2006). Sólo el amor es digno de fe. Salamanca: Sígueme.

Benveniste, É. (2001). Problemas de lingüística general (21a ed.). Buenos Aires: Siglo XXI.

Buenaventura, S. (1952). Breviloquio. En Obras completas. BAC.

Casullo, N. (2004). Itinerarios de la modernidad. Buenos Aires: Eudeba.

Concilio Vaticano II, G. e. (s.f.).

Congar, Y. M. (1961). Pentecostés. Barcelona: Estella.

Correa, J. V. (2000). Evangelizar la posmodernidad desde América Latina. Bogotá: Celam.

Eco, U. (2005). Tratado de semiótica general. México: De bolsillo.

Encíclica, M. (21 de junio de 1943).

Faus, J. I. (2006). Calidad cristiana. Santander: Sal Terrae.

Habermas, J. (2001). Israel o Atenas. (E. Mandieta, Ed.) Madrid: Trotta.

Harnack, A. V. (1904). La escencia del cristianismo. Barcelona: Imprenta de Henrich y Cia.

Heidegger, M. (1971). El ser y el tiempo (Cuarta ed.). México: Fondo de cultura económica.

Hipona, A. d. (1951). De la verdadera religión. Madrid: Bac.

Lyotard, J. F. (s.f.). Redescubrir la modernidad. Revista de occidente, 66.

Mardones, J. M. (2000). Postmodernidad y cristianismo. Santander: Sal Terrae.

Márechal, J. (1959). El punto de partida de la metafísica. Lecciones sobre el desarrollo histórico y teórico del problema del conocimiento (Vols. I-V). Madrid: Gredos.

Naisbit, J., \& Aburdene, P. (1990). Megatendencias 2000. Bogotá: Norma.

Peirce, C. S. (1974). La ciencia de la semiótica. Buenos Aires: Nueva Visión.

Quasten, J. (1984). Patrología. En Carta a Diogneto (pág. 247). Madrid. 
Rahner, K. (1963). Espíritu en el mundo. Barcelona: Herder.

Rahner, K. (1967). Oyente de la palabra. Fundamentos para una filosofía de la religión. Barcelona: Herder.

Rahner, K. (1971). Meditaciones sobre los ejercicios de San Ignacio. Barcelona: Herder.

Rahner, K. (2002). Escritos de teología (Vol. IV). Madrid: Cristiandad.

Rahner, K. (2007). Curso fundamental sobre la fe (Séptima ed.). Barcelona: Herder.

Rahner, K. (2008). Dios, amor que desciende, (Escritos espirituales). Santander: Sal Terrae.

Ricoeur, P. (1951). Del maestro. En P. Ricoeur, Obras completas (Bilingüe ed.). BAC.

Ricoeur, P. (1957). De doctrina cristiana. En P. Ricoeur, Obras completas (Bilingüe ed.). Madrid: BAC.

Ricoeur, P. (1980). La metáfora viva. Madrid: Cristiandad.

Ricoeur, P. (1988). Tiempo y narración. México: Siglo XXI.

Ricoeur, P. (1998a). Conflicto de las interpretaciones. México: Fondo de cultura económica.

Ricoeur, P. (junio-diciembre de 2000). De la interpretación del signo a la interpretación del texto. Universitas Philosophica (34-35), 51-52.

Ricoeur, P. (2000a). El conflicto de las interpretaciones. Buenos Aires: Fondo de cultura económica.

Ricoeur, P. (2001). Teoría de la Interpretación. México: Siglo XXI.

Saussure, F. d. (1979). Curso de lingüística general (Décima ed.). Buenos Aires: Losada.

Schillebeeckx, E. (1995). Los hombres relato de Dios. Salamanca: Sígueme.

Schütz, R. (2001). Die une peut qu'aimer. Ateliers et presses, Communauté-Taizé.

Thuan, C. V. (2000). Testigos de la esperanza. Buenos Aires: Ciudad nueva.

Zubiri, X. d. (1980). Inteligencia sentiente. Madrid: Alianza. 